Original Research Paper

\title{
Identifikasi Kemampuan Berpikir Kritis Siswa SMP Pada Materi Hukum Newton
}

\author{
Rizal Khasani $^{1 *}$, Shofwan Ridho ${ }^{1}$, Bambang Subali ${ }^{1}$ \\ ${ }^{1}$ Program Studi Magister Pendidikan IPA, Pascasarjana Universitas Negeri Semarang, Indonesia.
}

\section{Article history}

Received: December $6^{\text {th }} 2018$

Revised: April $29^{\text {th }} 2019$

Accepted: May 13 2019

*Rizal Khasani: Program Studi Magister Pendidikan IPA,

Pascasarjana Universitas

Negeri Semarang, Indonesia; Email:

rizalkhasani27@gamil.com

\begin{abstract}
This study aims to determine the critical thinking skills of junior high school students in Newtons Law material. This research is included in descriptive research with a quantitative approach. The research subjects were 28 students III A SMP Negeri 4 Belik. Data instruments were written tests of 10 multiple choice questions to measure students' critical thinking skills. The results showed that the student test results were $14.29 \%$ (very low category), $57.14 \%$ (low category), $10.70 \%$ (medium category), $14.30 \%$ high category) and $3.57 \%$ (medium category). ) very high). While achieving indicators of critical thinking skills for indicators: providing basic explanations (62.50\%), building abilities (55.40\%), concluding (25.00\%), making further explanations $(35.70 \%)$, strategy and tactics $(67.90 \%)$. Based on the results of the study it can be concluded that the critical thinking skills of class VIII A at SMP Negeri 4 Belik in Newtons law material are still low with an average score of 49.29 .
\end{abstract}

Key Words: Critical thinking ability; Newtons law

\begin{abstract}
Abstrak: Penelitian ini bertujuan untuk mengetahui kemampuan berpikir kritis siswa SMP pada materi Hukum Newton. Penelitian ini termasuk ke dalam penelitian deskriptif dengan pendekatan kuantitatif. Subjek penelitian adalah 28 siswa kelas VIII A SMP Negeri 4 Belik. Instrumen pengumpulan data berupa tes tertulis 10 soal pilihan ganda untuk mengukur kemampuan berpikir kritis siswa. Hasil penelitian menunjukkan perolehan hasil tes siswasebesar 14,29\% (kategori sangat rendah), 57,14\% (kategori rendah), 10,70\% (kategori sedang), 14,30\% (kategori tinggi) dan 3,57\% (kategori sangat tinggi).Sedangkan ketercapaian indikator kemampuan berpikir kritis untuk indikator: memberikan penjelasan dasar sebesar $(62,50 \%)$, membangun keterampilan dasar $(55,40 \%)$, menyimpulkan $(25,00 \%)$, membuat penjelasan lebih lanjut $(35,70 \%)$, strategi dan taktik $(67,90 \%)$. Berdasarkan hasil penelitian dapat disimpulkan bahwa kemampuan berpikir kritis siswa kelas VIII A SMP Negeri 4 Belik pada materi Hukum Newton masih rendah dengan rata-rata skor 49,29.
\end{abstract}

Kata Kunci: Kemampuan berpikir kritis; Hukum Newton

\section{Pendahuluan}

IPA menjadi salah satu mata pelajaran yang diajarkan di sekolah. IPA merupakan salah satu pelajaran yang dapat membangun pengetahuan, konsep dan juga dapat menumbuhkan kecakapan ilmiah, ketrampilan proses serta kemampuan berpikir kritis dalam memecahkan permasalahan yang terjadi didalam kehidupan sehari-hari. Sebagaimana yang tercantum dalam Permendikbud
No 64 Tahun 2013 tentang Standar Isi, menyatakan bahwa salah satu kompetensi yang harus dikembangkan pada mata pelajaran IPA adalah mengembangkan sikap rasa ingin tahu, jujur, tanggung jawab, logis, kritis, analitis, dan kreatif melalui pembelajaran IPA. Dari hal tersebut, agar tujuan dari pembelajaran IPA dapat terlaksana dengan optimal diperlukan kemampuan menganalisis dengan cara optimalisasi berpikir kritis siswa. 
Indonesia berada pada peringkat bawah dalam Human Development Index (HDI). Pada tahun 2013 Indonesia berada pada posisi 108 dari 177 Negara (UNDP, 2014). Hal itu semakin dipertegas oleh publikasi OECD (Organization for Economic Cooperation and Development) tentang hasil pengukuran literasi sains yang dilakukan oleh PISA pada tahun 2012 yang menunjukkan bahwa Indonesia berada pada peringkat ke-64 dari 65 negara anggota OECD dengan skor rata-rata 383. Hasil tersebut menunjukkan tingkat kemampuan berpikir kritis siswa Indonesia masih cenderung rendah. Berdasarkan hasil penelitian Gojkov (2015) kualitas jenjang pendidikan yang lebih tinggi dapat dilihat dari indikator kemampuan berpikir kritis siswa.

Menurut (Sanjaya, 2009) di Indonesia pembelajaran yang dilakukan masih kurang mendorong untuk ketercapaian kemampuan berpikir kritis siswa. Didalam pembelajaran yang dilakukan, siswa cenderung hanya sebatas menghapal materi yang disampaikan oleh guru. Menurut Patmah (2017), Pembelajaran yang berpusat pada guru (teacher center) mengakibatkan siswa tidak pernah melakukan persiapan sebelum pembelajaran dimulai. Hal tersebut mengakibatkan rendahnya minat belajar siswa. Hal ini dipertegas oleh penelitian yang dilakukan oleh Herliandry dkk (2019), yang menyatakan minat belajar yang rendah ditimbulkan dari pembelajaran yang kurang menarik, sehingga dapat mengakibatkan peserta didik menjadi enggan untuk belajar. Hal ini sesuai dengan penelitian yang dilakukan oleh Snyder (2008), bahwa proses pembelajaran yang mementingkan hafalan tidak dapat meningkatkan kemampuan berpikir kritis siswa. Menurut Latifa dkk (2017), kemampuan berpikir kritis adalah kemampuan yang dilibatkan dalam pengambilan keputusan. Menurut Nasir dkk (2015) guru harus merencanakan dan melakukan pembelajaran yang dapat mengembangkan kemampuan berpikir kritis siswa. Oleh karena itu, untuk dapat melaksanakan pembelajaran yang bermakna guru harus dapat melatih agar siswa dapat berpikir kritis dalam menganalisis maupun memecahkan permasalahan yang ada untuk mengambil suatu keputusan. Hal tersebut bertujuan mengembangkan kemampuan berpikir tingkat tinggi pada siswa. Salah satunya dengan menggunakan model pembelajaran yang dapat meningkatkan kemampuan berpikir kritis siswa seperti menerapkan Pembelajaran Berbasis Masalah (Problem Based Learning). Menurut Ismayawati (2016), Secara umum keterampilan berpikir kritis peserta didik dapat terbentuk karena pengkonstruksian proses belajar peserta didik yang dilaksanakan berdasarkan pembelajaran berbasis masalah. Hal tersebut sesuai dengan penelitian yang dilakukan oleh Dwijananti (2010), Sulaiman (2014) dan Nargundkar (2014) yang menyatakan bahwa Problem Based Learning dapat meningkatkan kemampuan berpikir kritis siswa.

Menurut Liberna (2013) kemampuan berpikir kritis adalah kemampuan dalam memecahkan suatu masalah dalam kehidupan sehari-hari dengan berpikir serius, aktif dan teliti dalam menganalisis informasi-informasi yang diterima dengan alasan yang rasional sehingga pengambilan keputusan yang dilakukan benar. Menurut Qurniati dkk (2015) dengan kemampuan berpikir kritis siswa dapat menganalisis pemikiran sendiri untuk menemukan pilihan dan menarik suatu kesimpulan. Hal itu sesuai dengan penelitian Kalelioglu (2013) bahwa kemampuan berpikir kritis dapat digunakan untuk memeriksa suatu kebenaran dari informasi yang diterima, sehingga dapat membantu siswa dalam memutuskan suatu informasi layak diterima atau ditolak. Hasil penelitian Wall (2015) menunjukkan bahwa untuk dapat menstransfer kemampuan berpikir tingkat tinggi pada siswa dapat dilakukan lebih mudah dengan menyatukan pengetahuan aspek berpikir tingkat tinggi dengan desain kurikulum yang sesuai.

Hukum Newton adalah salah satu materi IPA yang dapat menggali kemampuan berpikir kritis siswa. Oleh karena itu perlu untuk dilakukan identifikasi mengenai tahapan berpikir kritis siswa dalam penyelesaian masalah pada materi hukum newton.

Berdasarkan uraian tersebut, peneliti tertarik untuk mengidentifikasi kemampuan berpikir kritis siswa, khususnya siswa di SMP Negeri 4 Belik. Sesuai dengan masalah dan latar belakang yang telah diuraikan, maka peneliti mengambil judul "Identifikasi Kemampuan Berpikir Kritis Siswa SMP Pada Materi Hukum Newton". Tujuan penelitian ini adalah untuk mengidentifikasi kemampuan berpikir kritis siswa kelas VIII A SMP Negeri 4 Belik pada materi Hukum Newton.

\section{Metode}

Metode yang digunakan dalam penelitian ini adalah deskriptif kuantitatif. Subjek penelitian adalah 28 siswa kelas VIII A SMP Negeri 4 Belik tahun pelajaran 2018/2019. Penelitian ini dilakukan selama 2 minggu dengan menggunakan instrumen 
keterampilan berpikir kritis berupa tes tertulis dengan menggunakan 10 soal pilihan ganda. Dalam penyusunan instrumen tes berpikir kritis, peneliti berpedoman pada indikator materi yang digunakan dalam pembelajran IPA di sekolah dan indikator berpikir kritis menurut Ennis (1996). Data yang sudah diperoleh dianalisis secara destruktif.

Indikator ketrampilan berpikir kritis yang digunakan dalam penelitian ini terdiri dari 1) Memberikan penjelasan dasar, dengan sub indikator: memfokuskan pertanyaan, menganalisis argumen; 2) Membangun keterampilan dasar, dengan sub indikator: mempertimbangkan apakah sumber dapat dipercaya atau tidak, mengobservasi dan mempertimbangkan hasil-hasil observasi; 3) Menyimpulkan, dengan sub indikator: membuat dan mengkaji nilai-nilai hasil pertimbangan, menginduksi dan mempertimbangkan induksi; 4) Membuat penjelasan lebih lanjut, dengan sub indikator: mengidentifikasi asumsi, mendefinisikan istilah dan mempertimbangkan definisi. Strategi dan taktik, dengan sub indikator: memutuskan suatu tindakan.

\section{Hasil dan Pembahasan}

Hasil analisis kemampuan awal berpikir kritis siswa yang didapatkan melalui tes pilihan ganda menunjukkan lebih separuh dari 28 siswa kelas VIII A SMP Negeri 4 Belik tahun pelajaran 2018/2019 memiliki kemampuan tingkat berpikir kritis yang termasuk dalam kategori rendah yaitu sebesar $(57,14 \%)$ seperti pada Tabel 1.

Tabel 1. Kemampuan Awal Berpikir Kritis Kelas VIII A

\begin{tabular}{lll}
\hline Interval & Kategori & $\begin{array}{l}\text { Persentase } \\
\text { Nilai }(\%)\end{array}$ \\
\hline $20-35$ & Sangat Rendah & 14,29 \\
$36-51$ & Rendah & 57,14 \\
$52-66$ & Sedang & 10,70 \\
$67-82$ & Tinggi & 14,30 \\
$83-97$ & Sangat Tinggi & 3,57 \\
\hline
\end{tabular}

Hasil analisis indikator penilaian dengan menggunakan tes pilihan ganda pada materi Hukum Newton untuk mengetahui kemampuan berpikir kritis seluruh siswa kelas VIII A SMP Negeri 4 Belik ditunjukkan seperti tabel 2.

Tabel 2. Hasil Tes Ketrampilan Berpikir Kritis Kelas VIII A Pada Materi Hukum Newton

\begin{tabular}{|c|c|c|c|}
\hline $\begin{array}{l}\text { Indikator Ketrampilan } \\
\text { Berpikir Kritis }\end{array}$ & Sub Indikator Ketrampilan Berpikir Kritis & $\begin{array}{l}\text { Presentase } \\
\text { Jawaban } \\
\text { Siswa }(\%) \\
\end{array}$ & Kategori \\
\hline $\begin{array}{l}\text { Memberikan penjelasan } \\
\text { dasar }\end{array}$ & $\begin{array}{l}\text { 1. Memfokuskan pertanyaan } \\
\text { 2. Menganalisis argumen }\end{array}$ & $60,50 \%$ & Kurang Baik \\
\hline $\begin{array}{l}\text { Membangun keterampilan } \\
\text { dasar }\end{array}$ & $\begin{array}{l}\text { 1. Mempertimbangkan apakah sumber } \\
\text { dapat dipercaya atau tidak } \\
\text { 2. Mengobservasi dan mempertimbangkan } \\
\text { hasil-hasil observasi }\end{array}$ & $55,40 \%$ & Kurang Baik \\
\hline Menyimpulkan & $\begin{array}{l}\text { 1. Membuat dan mengkaji nilai-nilai hasil } \\
\text { pertimbangan } \\
\text { 2. Menginduksi dan mempertimbangkan } \\
\text { induksi }\end{array}$ & $25,00 \%$ & Kurang Baik \\
\hline $\begin{array}{l}\text { Membuat penjelasan lebih } \\
\text { lanjut }\end{array}$ & $\begin{array}{l}\text { 1. Mengidentifikasi asumsi } \\
\text { 2. Mendefinisikan istilah dan } \\
\text { mempertimbangkan definisi }\end{array}$ & $35,70 \%$ & Kurang Baik \\
\hline Strategi dan taktik & 1. Memutuskan suatu tindakan & $67,90 \%$ & Sedang \\
\hline
\end{tabular}

Dari tabel 2 diperoleh indikator memberikan penjelasan dasar sebesar $(62,50 \%)$, membangun keterampilan dasar $(55,40 \%)$, menyimpulkan $(25,00 \%)$, membuat penjelasan lebih lanjut $(35,70 \%)$, strategi dan taktik $(67,90 \%)$. Presentase rata-rata kemampuan berpikir kritis siswa dari kelima indikator yang ditunjukkan pada tabel 2 adalah 49,29 termasuk dalam kategori rendah.

Penelitian ini bertujuan untuk mengetahui kemampuan berpikir kritis siswa kelas VIII A SMP Negeri 4 Belik tahun pelajaran 2018/2019 pada materi Hukum Newton. Berdasarkan data yang diperoleh hasil dari pengolahan data yang telah dilakukan menunjukkan rendahanya kemampuan berpikir kritis siswa kelas VIII A SMP Negeri 4 Belik. Hal tersebut dapat disebabkan oleh beberapa faktor yang terjadi didalam kegiatan pembelajaran. Faktor-faktor tersebut diantaranya metode pembelajaran yang digunakan oleh guru, motivasi dan kesiapan siswa, fasilitas dan sumber belajar dalam pembelajaran materi Hukum Newton. Kemampuan berpikir kritis sebenarnya dapat 
ditingkatkan dengan salah satu caranya melalui penggunaan metode atau model pembelajaran yang tepat oleh guru dalam memberikan pembelajaran di kelas. Ada beberapa ide atau cara yang dapat diterapkan dalam pembelajaran seperti menyusun tempat duduk secara berkelompok, memberikan pengetahuan dasar sebelum memberikan pengetahuan yang lebih aplikatif pada siswa, memberikan beberapa pertanyaan yang dapat memebantu siswa dalam mengidentifikasi suatu masalah, melakukan evaluasi terhadap suatu fakta dan menyusun kesimpulan (Greenstein, 2012). Hal tersebut sesuai dengan penelitian yang telah dilakukan oleh Wisudawati dan Anggaryani (2014) bahwa kegiatan belajar dengan penggunaan metode atau model yang tepat sehingga siswa memiliki pengalaman dan cara kerja serta pemikiran yang terstruktur dapat meningkatkan ketrampilan berpikir kritis siswa.

\section{Kesimpulan}

Dari hasil penelitian dan pembahasan, diperoleh kesimpulan bahwa presentase rata-rata yang diperoleh siswa kelas VIII A SMP Negeri 4 Belik pada materi Hukum Newton yang meliputi lima indikator: memberikan penjelasan dasar sebesar $(62,50 \%)$, membangun keterampilan dasar $(55,40 \%)$, menyimpulkan $(25,00 \%)$, membuat penjelasan lebih lanjut $(35,70 \%)$, strategi dan taktik $(67,90 \%)$ termasuk dalam kategori rendah yaitu sebesar 49,29. Untuk menggali kemampuan berpikir kritis siswa, guru harus melakukan inovasi dalam pembelajaran. Salah satunya dengan menggunakan model pembelajaran yang dapat meningkatkan kemampuan berpikir kritis siswa seperti menerapkan Pembelajaran Berbasis Masalah (Problem Based Learning).

\section{Daftar Pustaka}

Dwijananti, P., \& Yulianti, D. (2010). Pembelajaran Problem Based Instruction Pada Mata Kuliah. Jurnal Pendidikan Fisika Indonesia, 6, 108-114.

Ennis, R. (1996). Critical thinking. Upper Saddle River, NJ: Prentice Hall

Herliandry L.D., Harjono, A., dan Ardhuha, J. (2019). Kemampuan Berpikir Kritis Fisika Peserta Didik Kelas X Dengan Model Brain Based Learning. Jurnal Penelitian Pendidikan
IPA,5(1).

https://doi.org/10.29303/jppipa.v5i1.166

Gojkov, G., Stojanović, A., \& Rajić, A. G. (2015). Critical thinking of students - indicator of quality in higher education. Procedia Social and Behavioral Sciences 191, 591-596. Diambil dari http://www.sciencedirect.com/ science/article/pii/S1877042815027615

Ismayawati, B., Purwoko A.A., dan Muntari (2016). Pengaruh Model Pembelajaran Berbasis Masalah (PBM) Dalam Setting Pembelajaran Kooperatif Tipe TGT DAN GI Terhadap Keterampilan Berpikir Kritis Dan Hasil Belajar Kimia Peserta Didik SMAN 1 AIKME Jurnal penelitian pendidikan ipa, 018.

Kalelioglu, F \& Gilbahar, Y. (2013). The Effect of Instructional Techniques on Critical Thinking and Critical Thinking. Education Technology \& Society, 17(1): 248-258

Nasir, M., Jufri, W., dan Muhlis (2015). Pengembangan Perangkat Pembelajaran Model 5E Untuk Meningkatkan Kemampuan Berpikir Kritis Siswa. Journal penelitian pendidikan ipa. 1(2)

Latifa, B. R. A., Verawati, N. N. S. P., dan Harjono, A. 2017. Pengaruh Model Learning Cycle 5e (Engage, Explore, Explain, Elaboration, \& Evaluate) Terhadap Kemampuan Berpikir Kritis Peserta Didik Kelas X MAN 1 Mataram. Jurnal Pendidikan Fisika dan Teknologi. 3(1): 61-67.

Liberna, H. (2013). Peningkatan Kemampuan Berpikir Kritis Matematis Siswa Melalui Penggunaan Metode Improve pada Materi Sistem Persamaan Linear Dua Variabel. Jurnal Formatif. 2(3), 190-197.

Organisation for Economic Co-operation and Development. (2013). PISA 2015 Draft Science Framework. Retrieved from http://www.oecd.org/

Patmah, Purwoko A.B., dan Muntari. (2017). Pengaruh Model Pembelajaran Learning Cycle 7E Terhadap Hasil Belajar Kimia Ditinjau Dari Kemampuan Berpikir Kritis Siswa. Jurnal Penelitian Pendidikan IPA. 3(2)

Pressure, P., Sediments, I. N., \& Front, I. N. (1985). Pri Enm. AAPG Continuing Education Course Note Series, 12(11), 773-776.

Qurniati, D., Andriani Y., dan Muntari. 2015. Peningkatan Keterampilan Berpikir Kritis Melalui Model Pembelajaran Discovery Learning. Jurnal Penelitian Pendidikan IPA. 3(1): 58-69. 
Sanjaya, W. (2010). Strategi pembelajaran berorientasi standar proses pendidikan. Jakarta: Kencana. Hal 60

Snyder, L.G., \& Snyder, M.J. (2008). Teaching Critical Thinking and Problem Solving Skill. Delta Pi Epsilon Journal. 50 (2): 90-99

UNDP. (2014). Human development report 2014. New York: UNDP

Wall, T. F. (2015). The Transferability of Higher Order Cognitive Skills. Procedia - Social and Behavioral Sciences, 174, 233-238. https://doi.org/10.1016/j.sbspro.2015.01.652

Wisudawati, A., dan Anggaryani, M. 2014. Penerapan Pembelajaran Fisika berdasarkan Strategi Brain Based Learning untuk Meningkatkan Keterampilan Berpikir Kritis Siswa pada Materi Elastisitas Kelas XI di SMA Negeri 1 Wonoayo Sidoarjo. Jurnal Inovasi Pendidikan Fisika. 3(1):1-5 